\title{
Sunflower oil production by utilizing Koya province agricultural crops
}

\author{
R. K. Abdulrahman \\ Chemical Engineering Department, Faculty of Engineering, \\ Koya University, Kurdistan Region-FR of Iraq
}

\begin{abstract}
In recent decades, the Kurdistan region of the Federal Republic of Iraq has faced huge developments in several life aspects; for instance, education, economic and the industrial sector. However, the industrial sector may still restricted in oil and gas industry. In fact, industrial developments have a huge rule in small cites developments and it has contributed in small cites' developments for instance, many of China's small cites have developed into huge cites in a few decades by the supporting of industrial sites. Indeed, establishing and operating several small projects for example, a sunflower oil factory, mineral water factory and tomato sauce factory will helps cities and counties with funding for housing, infrastructure and commercial rehabilitation that benefit people of low and moderate incomes. Sunflower oil may be considered one of the most important vegetable oils in the world. Its demand has been dramatic in recent years. Indeed, sunflower oil has several advantages over other vegetable oils and fats; for instance, high vitamin content, it is cholesterol free and has a nice flavor. Sunflower fields may be considered sustainable oil fields. Each year the agriculture land can produce thousands of metric tons of sunflower seeds that are saturated with high quantities of fresh oil. Indeed, Koya province possesses huge mails of green agriculture lands that depend on rainfall water. Therefore, this study aims to focus on sunflower oil factory projects in Koya city and its rules in Koya city developments as a part of a Koya city urban development workshop. The study showed that this project will have a huge impact on Koya city developments and economics as well. Moreover, the net profit of the produced fresh oil has been calculated without process operation cost which is about \$391 for one metric ton of seeds per one hour.
\end{abstract}




\section{Introduction}

Koya province is considered one of the leading provinces among Kurdistan Provinces which is opened to development and improvement and it has a rich historical background, natural beauties, underground resources, University, regional directorates, qualified labor force, efficient water resources and soil structure, huge agriculture lands. Koya city is located in the eastern part of Erbil city the capital of Kurdistan Region. Moreover, it has strategically location in middle of Kurdistan region of Iraq. Indeed, Koya agricultural province consists of four main agricultural sections, Koya section (agricultural land of Koya city and its villages) that has about 58,573 acres of arable land, Taq Taq that has about 47,907 acres of arable land, Ashti section that has about 28,335 acres of arable land, Shorash or Deigalla section which has about 92,865 acres of arable land. As a result, Koya province possesses 227,670 acres of arable land that depend on rainfall water [3]. The most obvious and important issue almost of these land depends on rainfall water, so it strongly considers economical agricultural land. Table 1 shows the main agricultural sections in Koya province and its areas as well.

Table 1: $\quad$ The main agricultural sections in Koya province and its area [3].

\begin{tabular}{|c|c|c|}
\hline No. & Agricultural section in Koya province & Area in acre \\
\hline 1 & Koya & 58573 \\
\hline 2 & Taq Taq & 47907 \\
\hline 3 & Ashti & 28325 \\
\hline 4 & Shorish & 92865 \\
\hline 5 & Total & 227670 \\
\hline
\end{tabular}

Mr. Hawez Muhamed and Mr. Jasim Nadir who work in Koya province agriculture planning section said that almost agricultural land in Koya province are suitable to planting sunflower seeds and it usually plants in March of each year and don't needs man irrigation because it depends on rainfall water and air humidity as well. The Koya farmers usually plant limited lands of sunflower seeds and sell their product in Koya city bazaar. Moreover, the quality of product is very good and it may contain $45 \%$ of fresh oil. Therefore, installing sunflower factory in Koya city may consider quite economical project and it will provide many jobs for Koya city people.

\section{Sunflower cultivation and seed sale prices}

Sunflowers are basically classified as helianthus annulus crops. It can be grown throughout the world because of their relatively short growing season [4]. The domesticated sunflowers typically have a single stalk topped by a large flower and it's significantly different from the smaller, multiply branched wild sunflower. Seed development then begins moving from the outer rim of the flower toward the center. It generally takes 30 days after the last flower is 
pollinated for the plant to mature. The sunflower plants reach various heights. The diameter of the flower heads is relatively large and typically between 7 and $15 \mathrm{~cm}$ [4]. Moreover, a common characteristic of sunflowers is a tendency for their flowering heads to follow the movement of the sun during the day. This phenomenon, called heliotropism, has the benefit of reducing damage from birds and preventing the development of disease. It is produced in warm temperate regions, Frost will damage sunflower at all stages of growth [2, 4]. The plant grows well within a temperature range of $20-25^{\circ} \mathrm{C}$. Sunflower will produce moderate crops with as little as $300 \mathrm{~mm}$ of rain, while $500-750 \mathrm{~mm}$ is required for better yields [4]. Table (2) shows the area harvested and yields (kg/ha) in the top producing countries [4].

Table 2: $\quad$ Top producing countries of sunflower seeds [4].

\begin{tabular}{|c|c|c|c|c|}
\hline \multirow{2}{*}{ Country } & \multicolumn{2}{|c|}{2006} & \multicolumn{2}{c|}{2007} \\
\cline { 2 - 5 } & Area & Yield & Area & Yield \\
\hline Russian & 5,943 & 1,136 & 5,003 & 1,131 \\
\hline Ukraine & 3,912 & 1,361 & 3,411 & 1,224 \\
\hline Argentina & 2,167 & 1,735 & 2,351 & 1,488 \\
\hline India & 2,118 & 580 & 1,880 & 778 \\
\hline China & 1,030 & 1,796 & 1,020 & 1,765 \\
\hline
\end{tabular}

As many other global markets, the global financial crisis seriously affected oilseed farmers, traders and processors through lower liquidity and increased cost of financing. After the extraordinary rise of sunflower seed prices in the spring of 2008 due to a poor sunflower seed crop in 2007 and overall global agricultural commodity price increases, sunflower seed prices started declining as crop production fully recovered in 2008. Figure 1 shows the sun oil and sun seed prices in USD per metric ton during various years.

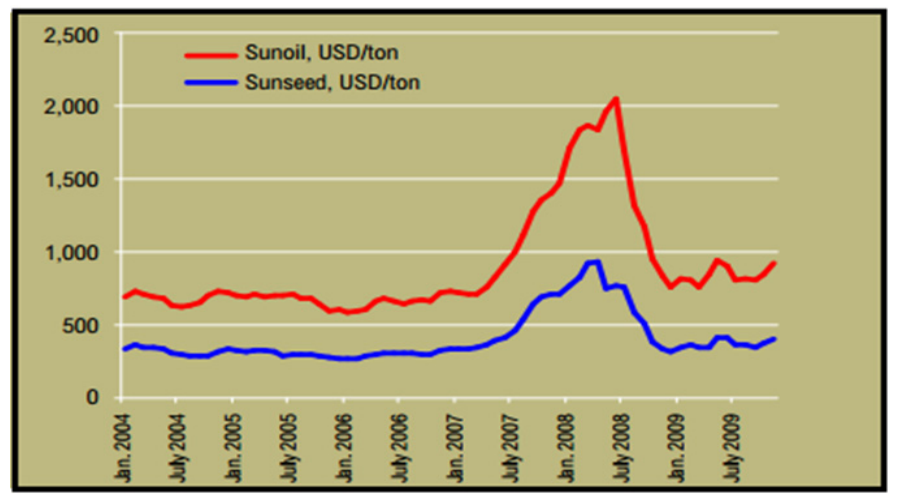

Figure 1: $\quad$ The sun oil and sun seed prices in USD per metric ton during various years [4]. 


\section{Sunflower oil process descriptions}

The production of sunflower oil from sunflower seeds can be achieved by two main methods, cold-pressed and chemical extraction. Indeed, chemical extraction method is more popular in commercial side and it is utilized a suitable commercial solvent such as, hexane. Sunflower oil manufacture involves cleaning the seeds, grinding them, pressing and extracting the crude oil from them, and further refining. Firstly, incoming oil seeds are passed over magnets to remove any trace of metal before being de-hulled [2]. The de-hulled seeds are then ground into coarse meal. The meal is then heated to facilitate the extraction of the oil. While this procedure allows more oil to be pressed out, more impurities are also released with the oil and these must be removed before the oil can be deemed edible. Secondly, the heated meal is then fed continuously into a screw press, which increases the pressure progressively as the meal passes through a slotted barrel [4]. Thirdly, extracting additional oil with solvents after the oil has been recovered from the screw press; the oil cake remaining in the press is processed by solvent extraction to attain the maximum yield. A volatile hydrocarbon (most commonly hexane) dissolves the oil out of the oil cake, is then distilled out of the oil and passes through the matter, to be collected at the bottom. Fourthly, removing solvent traces ninety percent of the hydrocarbon remaining in the extracted oil simply evaporates, and, as it does, it is collected for reuse. The remaining hydrocarbon is retrieved with the use of a stripping column. The oil is boiled by steam, and the lighter hexane floats upward. As it condenses, it too is collected. Moreover, refining the oil is next refined to remove color, and odor. Refining consists of heating the oil to between 40 and $85^{\circ} \mathrm{C}$ and mixing an alkaline substance such as sodium hydroxide or sodium carbonate with it. Oils are also degummed at this time by treating them with water heated to between 85 and $95^{\circ} \mathrm{C}$ steam, or water with acid [2, 4]. The gums, most of which are phosphatides, precipitate out, and the dregs are removed by centrifuge. Oil that will be heated is then bleached by filtering it through fuller's earth, activated carbon, or activated clays that absorb certain pigmented material from the oil. This procedure ensures that the oil will not partially solidify in the refrigerator. Finally, the oil is deodorized. In this process, steam is passed over hot oil in a vacuum at between 225 and $250^{\circ} \mathrm{C}$, thus allowing the volatile taste and odor components to distil from the oil. Typically, citric acid at $1 \%$ is also added to oil after deodorization to inactivate trace metals that might promote oxidation within the oil. Indeed, sunflower oil production is also produce valuable by-products is seed cake and I'm usually sold as a raw material for the production of animal feed $[2,4]$. Sunflower oil is liquid at room temperature and has the following characteristics:

Smoke point: $232^{\circ} \mathrm{C}$. Density: $917 \mathrm{~kg} / \mathrm{m}^{3}$, Viscosity: $0.04914 \mathrm{~kg} /(\mathrm{MS})$. Figure 2 shows the sunflower oil manufacturing process. 


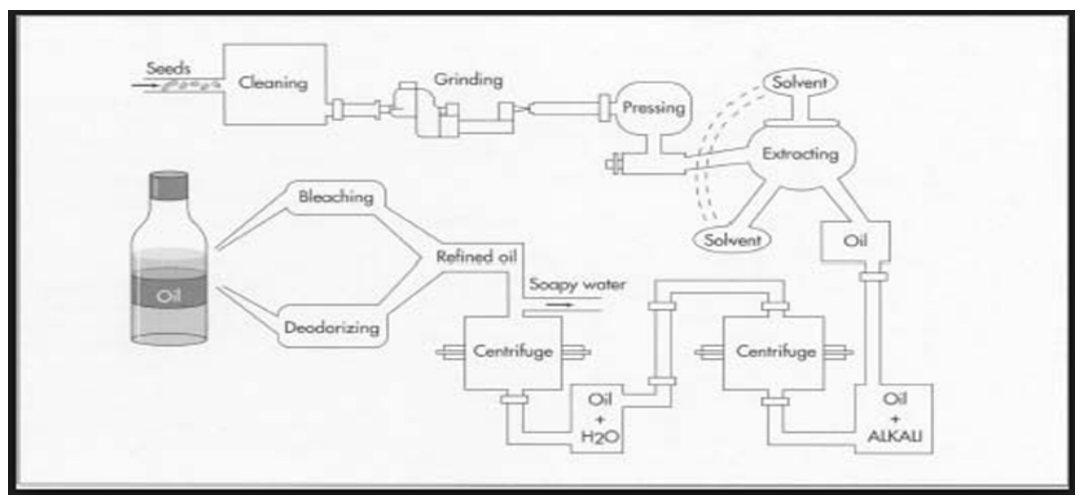

Figure 2: $\quad$ The sunflower oil manufacturing process [5].

\section{Case study of sunflower oil production}

In this research section, a case study of a moderate sunflower refinery will be describe vie material balance calculations. The case study assumed that the process feed is1000 Kilogram per hour of raw sunflower seeds that content about $44 \%$ of fresh oil [6]. Figure 3 shows the whole sunflower oil refinery process

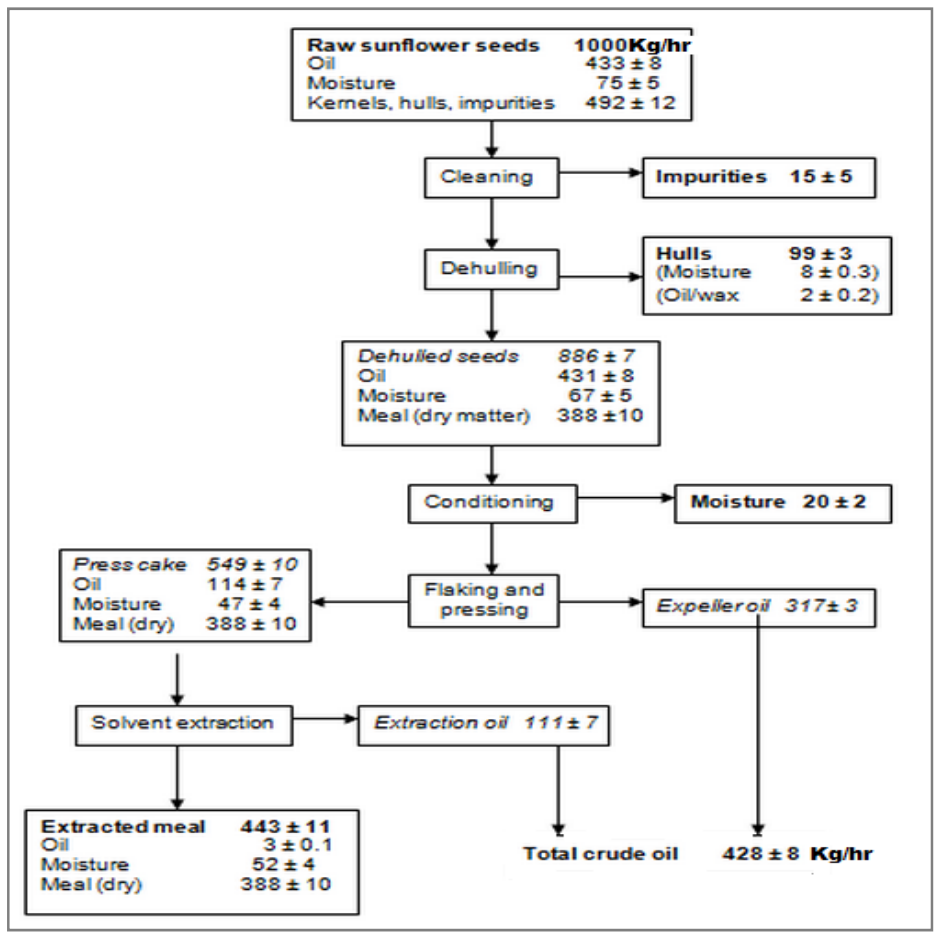

Figure 3: $\quad$ The whole sunflower oil refinery material balance [6]. 
material balance. Moreover, this process is utilized hexane as a chemical solvent to extract the oil from sunflower seeds.

The sunflower oil process material balance for $1000 \mathrm{~kg} / \mathrm{hr}$ of raw sunflower seeds is showed that it could produce about $428 \mathrm{Kg} / \mathrm{hr}$ of fresh sunflower oil.

\section{The process costs and profit}

According to FAO (Food and Agriculture Organization) investment center division, the capital investment in sunflower oil plant varies from USD (22,000 to 33,000$)$ and is on average USD 27,000 per one ton of daily capacity [4]. Moreover, this economic analysis is depended on European Union countries price and economics. However, the plan cost is cheaper in the Middle East region because it is nearest to China and other industrial countries that design and provide sunflower oil plant. Table 3 shows the breakdown of capital investment costs.

Table 3: $\quad$ The breakdown of capital investment costs [4].

\begin{tabular}{|l|c|}
\hline Total equipment costs & $37.5 \%$ \\
\hline main equipment & $30.0 \%$ \\
\hline supporting equipment & $1.5 \%$ \\
\hline Instruments & $16.7 \%$ \\
\hline transport & $3.3 \%$ \\
\hline Building and storage facilities & $12.5 \%$ \\
\hline Communications & $3.5 \%$ \\
\hline Construction infrastructure & $4.5 \%$ \\
\hline Mechanical works & $6.5 \%$ \\
\hline Pipelines and prot. surfaces & $6.0 \%$ \\
\hline Electric works and devices & $7.5 \%$ \\
\hline Land & $2.5 \%$ \\
\hline Maintenance and logistics & $1.5 \%$ \\
\hline Feasibility study and design & $10.0 \%$ \\
\hline Permits, licensing, etc. & $1.0 \%$ \\
\hline Contingencies & $7.5 \%$ \\
\hline
\end{tabular}

It seems that from the above table the majority of capital cost spends in refinery equipment which about $37.5 \%$ from the whole investment cost.

\section{Discussions}

The price of one liter of Turkish sunflower cooking oil in Koya city bazaar is about ID 2250 which equal to about USD 1.81. Basing on the assumed case study process, $1000 \mathrm{Kg}$ of raw sunflower seeds per hour is able to produce about $428 \mathrm{~kg}$ of sunflower oil so one liter of sunflower oil is equal to $0.98 \mathrm{~kg}$. Therefore, the assumed process could produce 437 liters of fresh sunflower oil from one metric ton of raw sunflower seeds which content about $44 \%$ of fresh oil. Moreover, the price of one ton of sun flower seeds in Asian markets such as, China and Malaysia is varied between USD500-1100 [7]. Moreover, Turkish 
sunflower seeds are cheaper than Asian seeds and are about \$200 per ton [7]. However, the price could be cheaper in Koya city because the expected sunflower oil factory will be closed to the raw material source and the local government may encourage the farmers to plant more agricultural areas with sunflower seeds. Therefore, let assume the one ton of sun seeds in Koya will be about $\$ 400$. Thus, one tone of sunflower seeds is able to produce 437 liter of fresh oil. Therefore, the basic profit will be about $\$ 791$ for one ton/hr of raw sunflower seeds. So the net profits for one ton raw seeds without process operation cost will be about \$391 for one ton of raw seeds per hour. As a result, it seems that the process will be quite profitable process.

\section{Contributions to Koya city development}

This study has attempted to show and describe the benefits of installing a sunflower cooking oil refinery in Koya city as a part of Koya city urban development workshop. Moreover, it is also examined a case study of sunflower oil refinery that proceed $1000 \mathrm{~kg} / \mathrm{hr}$ of raw seeds. It can argue that the installing and operating a moderate sunflower refinery plant at Koya city will be quite economical and beneficial to Koya city. It can also argue that the installing such project will encourage the people and farmers to invest more land to plant more crops. As a result, it will provide many jobs for Koya city people. Moreover, there are many good factors that could encourage the local and foreign investors to invest such project in Koya for example, the energy in Kurdistan region and Iraq is supported by government. Therefore, it is quite recommended that to install and operate sunflower oil project in Koya city.

\section{Acknowledgements}

R. Abdulrahman would like to thank Koya Province - Agricultural planning department, especially Mr. Hawez Muhamed and Mr. Jasim Nadir for their information and support as well.

\section{References}

[1] Dutt, A. The Asian City: Processes of Development, Characteristics, and Planning. Copenhagen: Springer, 1994.

[2] Gunstone, F. Vegetable Oils in Food Technology: Composition, Properties and Uses. Florida: John Wiley and Sons, 2011.

[3] Mr. Muhamed, H. and Mr. Nadir, J. stated in a personal conversation on August 6, 2013.

[4] FAO: Sunflower Crude and Refined Oils (20 Available at: http://www.responsibleagroinvestment.org/sites/responsibleagroinvestment. org/files/FAO_Agbiz\%20handbook_oilseeds_0.pdf. Accessed: 12 August 2103. 
82 First International Symposium on Urban Development: Koya as a Case Study

[5] Madhow site: Sunflower oil process [picture]. Available at: www.madehow.com. Accessed: 16 August 2013.

[6] Lipidlibrary: Lipid Chemistry, Biology, Technology and Analysis (2013). Available at: http://lipidlibrary.aocs.org/. Accessed: 18 August 2013.

[7] Alibaba: Sunflower seeds (2013). Available at: http://www.alibaba.com. Accessed: 23 August 2013. 